\title{
Dual Career of Elite Athletes in Greece
}

\author{
Aglaia Zafeiroudi (Corresponding author) \\ Department of Physical Education and Sport Science \\ University of Thessaly, Karies, Trikala, 42100, Greece \\ Tel: 30-243-104-7004Ｅ-mail: aglaiazaf@hotmail.com
}

\begin{abstract}
Asterios Patsiaouras
Department of Physical Education and Sport Science

University of Thessaly, Karies, Trikala, 42100, Greece

Tel: 30-243-104-7060Ｅ-mail: spats@pe.uth.gr
\end{abstract}

\begin{abstract}
Athanasios Dalamitros
Department of Physical Education \& Sport Science

Aristotle University, Thermi, 54124, Thessaloniki, Greece

Tel: 30-231-099-2185Ｅ-mail: dalammi@phed.auth.gr
\end{abstract}

\begin{abstract}
Alexandra Bekiari
Department of Physical Education and Sport Science

University of Thessaly, Karies, Trikala, 42100, Greece

Tel: 30-243-104-7040Ｅ-mail: sandrab@uth.gr
\end{abstract}

Charilaos Kouthouris

Department of Physical Education and Sport Science

University of Thessaly, Karies, Trikala, 42100, Greece

Tel: 30-243-104-7004 E-mail: kouthouris@pe.uth.gr 


\begin{abstract}
In the past 30 years, there has been extended research on athletes' career development toward a promising dual career. Present research was focused on the description of the legal and educational framework about dual career athletes in Greece, as well as on identifying the obstacles, needs and challenges of elite young and former athletes, and stakeholders in the development of their dual careers. A survey was conducted on a total of eighty-four athletes and stakeholders residents of northern, southern, and central sport destinations of Greece. Young athletes, former athletes and stakeholders completed three different questionnaires. Demographics, attitudes, preferences and actual experiences about their athletic life and career were recorded in parallel with their educational life and professional career. Data analysis supported that elite athletes in Greece neither seemed to follow a common model proposed by the state or national policy nor seemed to be supported by national legislation leading to dual-career practices. It was remarkable that sport stakeholders in Greece indicated that dual-career program remained at an early stage and more effort from all participants was required. A SWOT analysis pointed out strengths, weaknesses, opportunities and threats for the dual-career status in Greece. Results focused on the lack of support by the government, sports institutions, educational and market structures to link all forces successfully for a sustainable dual career program. Comparing to European sport system and strategies, the study revealed similar weaknesses and mainly the absence of an official national legislation.
\end{abstract}

Keywords: Career development, Stakeholders, Students-athletes, Career transition, Support

\title{
1. Introduction
}

A career can be broadly understood as a lifestyle that involves the sequence of work, learning and leisure activities through a lifetime (Career Industry Council of Australia, 2019; Rybaa, Ronkainenb, \& Selännec, 2015). Careers are unique to each person and are dynamic throughout life (McIlveen, Brooks, Lichtenberg, Smith, Torjul, \& Tyler, 2011). In the past 30 years, there has been an extended research on athletes' career development and the developmental pathways of an athletic career (Rybaa, Ronkainenb, \& Selännec, 2015; MacNamara, Button, \& Collins, 2010a; MacNamara, Button, \& Collins, 2010b).

Career Development Learning (CDL) relates to learning about the content and the process of career development of life (McMahon, Patton, \& Tatham, 2003). The content of CDL represents learning about self and learning about the world of a particular sport, study or work, while process learning is about the development of the competences and skills necessary to navigate a successful and satisfying life and career.

Based on this understanding, an athletic career appears to be just one part of the life career, which concerns athlete's future when retiring from sport to be well prepared for development in other spheres. That is, to provide flexible and competent support to talented athletes so that they can achieve their potential not only as sportspersons, but also as valued individuals in other domains of their lives. According to the holistic lifespan perspective (Wylleman \& 
Lavallee, 2004) and the holistic athletic career model (Wylleman, Reints, \& De Knop, 2013) athletes are considered as individuals doing sports alongside other spheres of their lives. Within this perspective, an athletic career is seen as an integral part of a life-long career.

\section{Theoretical Background}

The literature review will originally expand on concepts dealt with the central principles in the methodology of the present study. Those concepts are the main notions for linking active athlete's life with life and professional career after sports. Literature review reports athlete's dual career general in Europe and specific in Greek reality.

\subsection{Dual Career}

Dual Career (DC) is briefly defined as a career with major foci on sport and studies or work (Stambulova \& Wylleman, 2015). Pursuing education commitments while competing in high performance sport, however, can be a challenging task - the ever-increasing demands on performance in elite sports places high pressure on young athletes, who may often feel they are forced to choose between realising their athletic potential or obtaining a satisfying education for a post athletic career (Cosh \& Tully, 2015).

The DC trajectory is non-linear and actually consists of a series of different stages and transitions (Stambulova, Ryba \& Henriksen, 2016). Within each developmental stage and transition, athletes experience demands and challenges of various types and levels that may impinge on athletic and personal development (Minoudis, 2018). In other words, their investment in sport shifts over time according to context-specific social, psychological, and financial situation, educational commitments or work duties. This is even a more challenging task for the non-professional athletes, who often have to manage their sporting careers within limited cognitive, social, financial and temporal resources or not well organised DC support structures.

Elite athletes' DC has recently received political legitimacy from the European Union, underpinned by a growing concern with some national sport cultures and sport-specific subcultures which permit the exploitation of young athletes without paying appropriate attention to their educational and further occupational needs thus exposing them to potentially inequitable situations during and after retirement from sport. The strategic document, EU Guidelines on Dual Career of Athletes (European Commission, 2012), demonstrates the supportive institutional approach of the EU in relation to DC, especially the need of concerted efforts on the protection of their basic right for equal access to quality education. This represents an explicit political and social recognition of the issue of athletes' DC by both the EU institutions and national governments. It should be stressed that such an approach necessitates the creation of intersubjective meanings which go beyond individual beliefs and a mandate for action.

\subsection{Dual Career in Greece}

Despite the widespread participation in sports during last decades in Greece, especially before and after 2004 Olympic Games, the existing legislative framework regarding athletes' educational career combining with their sports progress remains unspecified. In addition, every year a new legislation seemed to come up affecting youth participation in Greece. 
Significant privileges that characterized athletes' future educational career is under abolition nowadays.

More specifically, the Greek Council of State recently decided (686/2018) that elite athletes cannot freely enter in any public higher educational institution, as used to be for many decades. The decision was based on the idea that this action violates the constitutional principles of equality and meritocracy among all the other candidates that intend to be university students. The law for the free entry of distinguished athletes to any university school applies only to athletes with a first to third victory in the Olympics or World Championships. The athletes with a forth to sixth victory are charged a percentage increase depending on the place of distinction for admission to any university department or the department of physical education and sport science.

Furthermore, an important support tool in the country was public sports schools that were created during 80's and 90's and now are closed. After three decades of operation, in 2010 (in the beginning of the Greek economic/financial crisis) the government was phasing out sports schools as they costed too much and have been deemed by the Ministry of Education to be "counterproductive for sport and unconventional for education". According to the Ministry of Education, 12,060 students were studying at public sport schools. In addition, 2,036 teachers of physical education and other specialties were employed. The cost of this operation was about 25 milions euros every year. Of this amount, about 2.4 million were spending on student needs like traveling and transportation. A relevant legislation, which prevents the development of an athlete's career in Greece, is the following. The Greek sports law 2725/1999 art.108 (as modified by the law 3479/06, art. 13), clearly states that athletes' obligations include their maintenance in the same sports club until the age of twenty-three. In a different case, it was prohibited to participate in any competition for two consecutive years. This legislation leads athletes to quit their sport in an early stage, resulting in high dropout rates of competitive sport during the teenage years. Thus, the law seemed to protect primarily the rights of the sports clubs than the potential competitive career of an athlete. However, the law 3479/2006 (art. 4), also provides the opportunity for training programs that could also be offered to amateur athletes based on an appropriate and well-founded argumentation and interpretation.

A privilege of elite athletes that still exists, but it does not enhance the athletes' dual career processes is referred below. Traditionally in Greece athletes that achieved high-level performance during Olympic Games or World championships ( $1^{\text {st }}$ to $3^{\text {rd }}$ place) are still offered a (permanent) job in the public sector (e.g., central government, local government, health sector, education, army, etc.), according to their qualifications and preferences. In addition, as a privilege, high-level athletes are exempted from any military service, which nowadays as an obligation to male citizens.

At the same time, elite athletes were taken advantage of the privileges, which derived from the guidelines of the European Union (EU) concerning the DC (European Commission, 2012). More analytically, specific actions are aiming at accomplish the goals of Europe 2020 strategy including the prevention of leakage of students, higher employability, as well as keeping more athletes active for a longer time. Moreover, the EU is moving towards encouraging higher education institutions to collaborate with sports organizations to design 
distance-learning programs for active and non-active athletes in the frame of dual career (good practices). As an example, a handbook of best practices funded by the European Commission through the Erasmus + Sport Program, involving seven countries, including Greece, was published in 2017 (DC4AC, 2017). Finally, another obstacle during an athlete's career refers to athletes' difficulties to find sponsorships from companies due to a reduction in the reciprocal economic relief of businesses in national and international context (DC4AC, 2017; López de Subijana, Barriopedro, Conde, 2015)

Summarizing, based on the laws of Sport Ministry (2725/99) and the recent laws of the Ministry of Education on primary, secondary and higher education (4547/2019) it is obvious that in Greece there is a 'gap' of a specific legislation or a strategic plan to support athletes' 'life after sport' by either the state or the sports agencies. In fact, there is no provision for the athletes' future employability. Moreover, continuing education and the enhancement of athletes' educational training in terms of a program that can facilitate a positive transition from the sports environment into post-sports life, or combining a career in sports, with an academic career, is missing too.

\section{Objectives of the Study}

The present research aimed i) to investigate Greek athletes' actual needs, obstacles and expectations concerning dual-career, ii) to report the legal, political, organizational aspects, and educational framework and iii) to inquire into stakeholders' actions and endeavours in order to facilitate and enhance a mutual and sustainable athlete's dual-career policy.

\section{Method}

\subsection{Participants}

A total of eighty-four athletes and stakeholders were participated:

i) Thirty-six young athletes (53\% male and $47 \%$ female), between the age of 14-18 years old participated in the study, represented three parts of Greece, northern part (50\%), central part $(36.1 \%)$ and southern part (13.9\%) as elite athletes from eight different sports. Athletes were actively engaged in their sports career with an average of 7.4 years of sports meetings and championships with $10 \%$ participation in World/or European championships and 35\% participation in national championships. From them, 55\% did not succeed in any significant sports achievement during their sports career. From the participants, $44.4 \%$ did not have problem in coordinating their academic obligations with their sport commitment, but $45.6 \%$ participants answered that had serious problems in coordinating their academic obligations with their sport commitment. Lastly, $43 \%$ of the participants have been supported in the process of developing a dual career mainly by their family.

ii) Thirty-two former athletes (50\% male and 50\% female), between the age of 25 and 34 years old, participated also in the study, and they were actively engaged in nine different sports, $50 \%$ in team sports and $50 \%$ in individual sports. They started their sport career from the age between 5 and 14 years old (Mean=10.8) and they ended their sport career because of family $(31.3 \%)$, lack of support (25\%), health reasons (18.8\%), age $(12.5 \%)$.

iii) Sixteen stakeholders participated in the study. Stakeholders professional positions consisted by default of the Director of Training Department from the General Sports Secretary in Greece, the President of Hellenic Volleyball Federation, the President of 
Hellenic Judo Federation, the President of the Volleyball coaches association, 2 technical directors of Hellenic volleyball Federation, 2 technical directors of the Hellenic Track and field Federation, 3 national team coaches, one sports club manager, one high-rank public education sector official and 2 school counsellors at secondary education. All participants served in their section a couple of years and had national and international recognition in sport and/or in the educational area.

\subsection{Instrumentation}

Three different questionnaires were developed within the framework of the European Educational program Erasmus+ Collaborative Partnership, 'Life After Sports'. Participants completed the three different questionnaires for young athletes, former athletes and stakeholders respectively, as follows:

\subsubsection{Questionnaire for Young Athletes}

The questionnaire consisted of thirty-one items developed in order to explore the needs and obstacles of young athletes during their education and sports career and gain insight to their personal experiences of DC. From them, five items referred to personal information-demographics characteristics and twenty-six items investigated athletes' sports status, interest in education, career support and the conditions that were considered necessary for a quality solution of dual career. Twenty items were answered at multiple-choice format or at a 7-point Likert scale (e.g. How often do you miss school lessons because of sports obligations? a. Most of the school year, b. Several times a week, c. Several times a month, d. I rarely miss), three were dichotomous questions (e.g. Are you planning to continue your education after high school?), and finally the rest were three semi open questions (e.g. What else could help you further to develop a DC (sports \& education) with respect to the sport you are engaged in?).

\subsubsection{Questionnaire for Former Athletes}

The questionnaire consisted of twenty-five items developed in order to record former athletes DC history/trajectories, critical development decisions, education level (formal/informal), career path preferences, external influential experiences and factors that assisted the development of DC support strategies. First seven items referred to personal informationdemographics characteristics and eighteen items reported sports status, main challenges when transiting into the labour market, skills and competencies developed through engagement in sport, the support of the community and the conditions considered necessary for successful achievements in both sports and education. From them, thirteen items were answered at multiple-choice form or at a 7-point Likert scale (e.g. What period was the hardest one for you to combine your educational and sporting commitments? a. Primary school b. Secondary school c. University), one item was referred to a dichotomous question (e.g. Which role did you most identify yourself with? a. Academic role b. Athletes' role), and finally there were four semi-open questions (e.g. How does your sports background help you in your present job?).

\subsubsection{Questionnaire for Stakeholders}

The questionnaire was developed in order to record sports stakeholders' opinions, perceptions and actions about dual-career policies, strategies, processes and practices were applied by 
sports organizations. Nineteen questions interviewed the individuals possessing high administrative positions at the most important organizations, or players in the sport industry. From them eighteen questions answered at multiple-choice format (e.g. In your opinion who should take the responsibility for dual career enhancement in your country? a. European b. Community c. National d. Parliament e. Ministry of Sport f. Ministry of Education Federations/Sport Association g. Private h. Organizations), and one semi open question (Please refer any dual career programmes you are aware or other Good Practices).

\subsection{The Procedure}

A detailed data analysis conducted by three researchers with previous participation and experiences in elite sports career. Beyond statistics for demographic data that was a typical process to score, items scored by semi-open answers were analysed similarly to a qualitative analysis process.

\section{Results}

Result's presentation of the study followed the three different questionnaires context:

Results analysis of young athletes showed that most of athletes' decisions about their sports career and educational career shaped according to their close environment. Each athletes' individual environment appeared the same factors that influenced decisions about future sport career and education processes. These factors were their family, their school environment, their sports coaches and the specific conditions/management that dominated on their sports club/team.

It is also important to point out the absence of any care or help from the local authorities. Athletes' parents were more interested in their children's receiving an extra opportunity to participate in a future famous international sport meeting, or to receive a financial bonus, than taking care of the creation or the enhancement of dual-career conditions. The relationship between schools and athletes was focused on justifying more absences than enhancing teaching. Elite athletes in Greece neither seemed to follow a common model or good practices proposed by the state or national policy nor seemed to be supported by national legislation leading to dual-career practices.

Results analysis of former athletes showed a common direction, suggesting that any athletes' decision in their sporting career was made by their own or in cooperation with their close environment, educational, sporting or family. No one mentioned the existence of a specific program responsible to support athletes during their studies and sports career. However, all former athletes stated that they gained many skills and competencies from their sports careers such as cooperation, discipline, communication skills. They mentioned that no national or another type of supportive programme or legislation prepared them what to do after their active sports life.

Stakeholders' results revealed the evidence that dual career programs are neither well known nor very popular in the Greek sports community. Despite that ascertainment, stakeholders expressed the necessity that these programs should offer a transition from sports reality to the post-sport life. Almost all stakeholders' organizations offered support for their athletes, primarily for sports training development and performance, medical support and rehabilitation after a sports injury, or the provision of 'pocket-money'. The Greek government 
supported financially the sports programs through Sports Federations, public education, other organizations, sports clubs etc. In most cases, those offers limited to high-level athletes or the winners of a championship.

They were no specific dual-career programs to help the athletes who were not already under the umbrella of the Greek government athletic support program. Due to this situation, the stakeholders reported that mostly the parents of young athletes communicated with them asking for support (financial, psychological) for their children. Only one federation in Greece seemed to be aware of life after sport career mainly concentrated on the athletes played in the National team. This was the Greek Volleyball Federation.

The information about the existence of dual-career programs, unfortunately, was restricted on the presidents of federations, associations, and technical directors. All of them expressed the necessity of these programs in order to help athletes in the transition from sport to "normal life', but they did not finance any resources. Especially, the stakeholders in the public education sector should have the opportunity and the information of dual career program in order to disseminate these programs in young athletes in schools. All of the stakeholders referred to the lack of Greek national law or legislation concerning the support of a dual career in athletes. Furthermore, the cooperation of government bodies with clubs or associations in this area was at an early stage of development.

Nevertheless, it was quite doubtful how effectively these principles were implemented. Practitioners (experienced athletes, managers of sport-related agencies and stakeholders) were interviewed and were ascertained that there are no specific supportive policies for the dual career, or these policies occasionally are not applicable fair. For example, some stakeholders from the education organizations appeared to be pessimistic or even critical about a transparent character of athletes networking privileges and the social inequality of supporting between students and athlete students who have dealt with the sport as elite athletes. They considered that school progress could not be a secondary issue for student-athletes, while other social groups of youth (e.g. long-studied students) after their graduation were under the necessity migrate because of lack of support by the state for employability despite their excellent grades.

In addition, stakeholders stated the importance of these programs. They insisted that the EU ought to cooperate with the national governing bodies such as the Ministry of Culture and Sports toward the development of dual-career programs. Additionally, stakeholders referred that EU and state authorities were the only responsible organizations that could take action to enhance dual-career good practices in Greece.

The results of the interviews by stakeholders in Greece revealed that dual-career program was at an early stage and more effort from all participants in that area was essential. The general problem was the vague limits of the athletes who wanted to work during and after their sports career. The offers by stakeholders limited to seminars, sport-specific education offers and some financial support. Note that due to the financial crisis in Greece, the available financial programs were limited too. As it was already referred, the stakeholders from the public education section were not at all aware of the existence and/or the usefulness of programs such as Life After Sport (LAS) or other dual-career programs that provided help for the athletes after the termination of their athletic career. 
Combining the above results and information derived from the three questionnaires analysis, a SWOT analysis was a prominence to point out strengths, weakness, opportunities and threats for a dual-career in Greece (Table 1). SWOT analysis of Athletes and stakeholders perceptions about dual career in Greece are presented in Table 1.

Table 1. SWOT analysis: Athletes and stakeholders perceptions about dual career in Greece

Internal origin attributes

\section{Strengths}

- Continue the actions of individual stakeholders implementing dual-career programs in the country (volleyball federation).

- Continue the provision of privileges and facilitations to athletes by the state.

- Continue the favourable address of athletes' demands to justify absenteeism's by educational organizations.

\section{Opportunities}

- Continue the creation of European Union dual career programs for national and transnational applications.

- Disseminate the need for dual career programs throughout society.

- Creation of supportive programs to facilitate the needs of pupils / students through actions by educational organizations (schools, universities, federations, ministries).

External origin attributes

\section{Weakness}

- The economic crisis in the country.

- The wrong perception of athletes and their parents to be primarily interested in sports careers rather than dual career programs.

- Misunderstanding of educational organizations stakeholders that dual career programs favour athletes over other students

\section{Threats}

- Staying inactive and failing to create national laws and practices for dual career in the Greek territory.

- Continuing misinformation by media that 'a successful athlete career' automatically solves the issue of living.

- Maintaining individual actions or possibly no action by elite athletes for dual careers and failing to aggregate their claim to a powerful joint claim.

\section{Discussion}

This research has been focused firstly to investigate Greek athletes' actual needs, obstacles and expectations concerning dual-career, secondly to report the legal, political, organizational aspects, and educational framework and thirdly to inquire into stakeholders' actions and 
endeavours in order to facilitate and enhance a mutual and sustainable athlete's dual-career policy. The results carried out from the group of athletes and former athletes and stakeholders at a national level.

The main conclusion of the research was that Greece have legislations that try to regulate the framework of educational support for elite athletes, but legislations remained old fashioned, not enough to cover the issue, and is required to be updated. It is necessary to be designed new strategies that allow tackling successfully the new / modern challenges faced by athletes regarding their training conditions, their education and the development of a future professional activity. Furthermore, the main needs identified were:

a) To cover the need for educational and sports institutions support and coordination. To develop a common system and structure, a network of tutors and mentors with specific training to guide athletes from the young age during school age and later during their academic studies. Provision of support by expert staff who, through athletes' supportive service, help and guide them on the development of their sports career.

b) To make the "socializing agents" (parents, coaches or club managers, stakeholders etc) organize themselves in collaboration systems and networks to receive specific training on the aspects of dual careers of athletes during all the stages of their sports career: initiation, development, mastery and retirement.

c) To enhance and develop more communication and cooperation between educational, sport, health system, government institutions and work market/companies in order to develop more structured aids adapted to the new circumstances of athletes: scholarships, balance and flexibility of schedules, online learning methodologies, tutoring, or greater federative support, funds, work education for athletes.

d) To create more quality online educational projects and methodologies for the education of athletes from early to young age.

e) To design a new well-structured dual career program in National /European level and promote its significant guidelines and its adoption.

In more detail, the researchers reported the existence of incomplete dual-career legislation, old, unorganized that required to be updated urgently. In this process should be taken into account the data of the new 21 st-century society, the evolution and the transition of the industrial society and its educational systems towards the network society, as well as the new requirements with respect to the global labour market trend and the new professions. The main issues should be taken into account for the development of a new DC legislation were:

- Provide student-athletes with more flexibility in studies.

- Promote DC topic and raising the knowledge and awareness about DC demands and benefits, thus trying to reduce the stereotypes of teachers and other educational representatives about sportspeople.

- Create new DC programs, especially to allow the process for successful DC that should provide skills and qualifications for post-athletic life, without compromising athletes education accomplishments for the sake of their sporting pathways, thus making both possible, while keeping the high quality on both parts. 
- Introduce a special training module on career management/education in the curricula of sport schools and students, who are not only current athletes but also future coaches.

- Build on the expertise and input by career development consultants and academic scholars in devising DC support strategies and programs.

- Introduce the topic of DC in the sports development plans of sport federations and member clubs, through enforcing a special policy, a set of minimal standards of DC services provision and incentive mechanisms to sports governing bodies receiving public subsidies.

- Insert the athletese DC issue in the Sport Law, which would constitute a political recognition of this crucial policy area and provide a formal ground for institutional actions.

- Adopt an inter-institutional approach to the DC policy making and implementation process by establishing an ongoing, open dialogue and a task force expert group comprising representatives of the key stakeholders from the sport community, educational sector, employers' associations, career experts, academics, former athletes and parents.

- Establish a cooperation with other bodies that are responsible for questions dealing with sports, education, employment, defence, interior affairs, economy, health and finance as well as sports organizations, educational institutions, employers and others.

- Provide funds for carrying out activities planned for a one-year period and connected to the implementation of the National Programme of Development.

- Encourage institutions to define minimal conditions and professional assistance for young athletes.

- Develop individual programmes of special care of the young athletes of 12 to 16 age.

- Cooperate with the Paralympic Committees planning activities for categorised athletes with disabilities.

- Encourage as many institutions possible to define acts that will regulate dual careers (not only in sports but also in other activities that demand substantial devotion of students such as music, ballet, etc.).

- Establish clubs that inform athletes, good practice examples, promote athletes who made a career after their sports career, establish interests of athletes who ended their sports career, etc.

- Develop an information system through National and European Sports Federations about raising awareness among athletes and the importance of dual careers and the Career Support Programme.

- Define, through National and European Sports Federations, regulations and plans where certain measures and activities will be elaborated along with athletes' and clubs' commitments with regard to the interest of athletes, available infrastructure and other conditions (the vicinity of an educational institution, professional assistance and support, cooperation with the educational institution, cooperation with the employer etc.).

- Establish through National and European Sports Federations needs and interests, informing and promoting dual careers at coaching seminars and sports occasions, pointing out other competencies of athletes besides sports results 
- Promote the role of dual careers (meetings, workshops, sports occasions) and educate coaches about athletes' dual careers.

- Establish a cooperation with the educational institutions where athletes are schooled/educated and conducting programmes which will enable the continuation of their career in the club after the end of their sports career.

- Point out role models, for example, former athletes and coaches who successfully continued their careers in sports or any other professions after the end of their sports career.

- Develop a specific DC parenting education for fully developing a positive role for DC decisions of their children, especially at the end of the high school when elite athletes are at risk of terminating their education. These programmes should aim to help parents understanding and managing their roles in DC of talented and elite athletes, and to proactively develop and utilize a range of intrapersonal, interpersonal and organizational skills and coping strategies to ensure an appropriate DC parental support.

- Establish dual career structures and agreements with national and European sports federations, interventions to all academic/sports environment and involving a big number of elite athletes at national and European level.

- Develop educational, training and learning projects for dual career services, through new technologies applied to education (e-learning).

All the above proposals could be implemented through the creation of a new law at national or European level that will support and link all the structures needed for a successful Dual Career program. In order to create new legislation in support of dual careers at national level there should be a more effective code of communication between sports bodies and organizations such as Ministries of Sport, National Olympic Committees, athletes' representatives and former athletes. A new national strategy is necessary, implying an update aimed at generating the agenda of dual career that incorporates new issues and challenges, that considers all actors, and that is aligned with the new requirements of the globalized society.

Investigating sports and the existence of a dual career in Europe through, it appears that DC is a complex phenomenon incorporating several intertwined dimensions of student-athletes' life. A multi-sectoral approach is necessary to address intersecting and interacting elements of this complex issue. These include parents, coaches, counsellors, psychologists, athletes, former athletes, stakeholders, school instructors and principals, social, economic and cultural aspects as well as clubs, schools, universities, sports associations, federations, committees, government institutions and global labour market. Students-athletes act in a very complex environment of people and institutions. In order to create an efficient dual career path for student-athletes, all relevant social, economic, educational and sports structures should be on the same point to act in coordination together.

All above require a collective understanding of DC and institutions to focus on intersecting and interacting elements of this complex issue. Therefore, both the EU and individual member states approaches to athletes' DC represent a par excellence form of intentional development which, as Cowen and Shenton (1996) argued, is concerned with the deliberate policy and actions of the state and other agencies, which were expressed in various 
developmental visions. This helps to link the intent to develop (visions) with agency through the notion of trusteeship.

\section{Conclusion}

Creating and promoting a dual career for the athletes is critically important not only for the sport industry but also for the labour and the whole society. Balance is the key to success in life. The athletes need to find the right balance between training efforts and learning but also between the entrance at the labour market and training, which is a consistently challenging phenomenon. Investigating national, European sports and dual-career programs it appears that governments and the sports industry are limited to provide help and support toward high sports performance and don't cover the lack of athletes' education which is necessary for the life after career. It is obvious that there is a grey zone in the supporting efforts that operate by the government, sports sector, educational institutions, market forces and social structures.

Today, this ever-increasing sports competition, the demand to over-the-top performance and the growing economic activity, have dramatically increased the "life obligations" of elite athletes. Consequently, the balance between training and living has been disturbed. Human should seriously consider the fact that sport seems to no longer serve the man, but the man be used by sport as part of the global spectacle, the supreme performance, the technology, the commercialization. In the end, it might not just be worth only exploring the dual-career offerings and its inclusion in athletes' sports career.

Perhaps it is now more imperative than ever, the process of sport should be further explored, and then be redesigned, be redefined and re-based on its true human nature and value rather than superman's reality.

\section{Acknowledgement}

The present research is part of the European Educational program Erasmus + Collaborative Partnership, 'Life After Sports', code 603311-EPP-1-2018-1-BG-SPO-SCP, Bulgaria, Greece, Croatia, Turkey, Italy, and Spain, and is used as promotional material to communicate and disseminate the project into the academic community.

\section{References}

Career Industry Council of Australia. Professional Standards for Australian Career Development Practitioners (2019). [Online] Available: https:/cica.org.au/wp-content/uploads/Professional-Standards-for-Australian-Career-Develop ment-Practitioners-2019.pdf (April 14, 2020)

Cosh, S., \& Tully, P. J. (2015). Stressors, Coping, and Support Mechanisms for Student Athletes Combining Elite Sport and Tertiary Education: Implications for Practice. Sport psychologist, 29(2), 120-133. https://doi.org/ 10.1123/tsp.2014-0102

Cowen M., Shenton, R. (1996). Doctrines of development. Routledge, New York.

DC4AC Dual Career for athletes center (2017). Actual status of Dual Career of Athletes in DC4AC Countries - $\quad$ National Reports. [Online] Available: http://dc4ac.eu/Actual\%20status\%20of\%20DC\%20in\%20participating\%20countries.pdf (April 2, 2020) 
European Commission EU guidelines on dual careers of athletes: Recommended policy actions in support of dual careers in high-performance sport. Brussels: Sport Unit, European Commission Education. [Online] (2012). Available: https://ec.europa.eu/assets/eac/sport/library/documents/dual-career-guidelines-final_en.pdf (March 29, 2020)

Greek Council of State (686/2018). [Online] Available: http://www.dsanet.gr/Epikairothta/Nomologia/steol686.html_(April 5, 2020)

Greek Sport law (2725/1999). [Online] Available: https://www.e-nomothesia.gr/kat-athlitismos/n-2725-1999.html_(April 3, 2020)

Greek Sport law (3479/2006). [Online] Available: https://www.e-nomothesia.gr/kat-athlitismos/n-3479-2006.html_(April 4, 2020)

López de Subijana, C., Barriopedro, M., Conde, E. (2015). Supporting dual career in Spain: Elite athletes' barriers to study. Psychology of Sport and Exercise, 21, 57-64. https://doi.org/10.1016/j.psychsport.2015.04.012

MacNamara, A., Button, A., \& Collins, D. (2010a). The Role of psychological characteristics in facilitating the pathway to elite performance part 1: Identifying mental skills and behaviors. The sport psychologist, 24(1), 52-73. https://doi.org/ 10.1123/tsp.24.1.52

MacNamara, A., Button, A., \& Collins, D. (2010b). The Role of psychological characteristics in facilitating the pathway to elite performance part 2: examining environmental and stage-related differences in skills and behaviors. The sport psychologist, 24(1), 74-96. https://doi.org/10.1123/tsp.24.1.74

Mcllveen, P., Brooks, S., Lichtenberg, A., Smith, M., Torjul, P., \& Tyler, J. (2011). Career development learning frameworks for work-integrated learning. Developing Learning Professionals, 149-165.

McMahon M, Patton,W, Tatham P. (2003). Managing life learning and work in the $21 \mathrm{st}$ Century. [Online]

Available: https://pdfs.semanticscholar.org/d393/a838fb8d41c9ad24a12d7b16c832e782b61a.pdf?_ga=2. 132767502.1695218439.1595483136-717279916.1578213036 (April 15, 2020)

Ministry of education (4547/2019). [Online] Available: https://www.e-nomothesia.gr/kat-ekpaideuse/nomos-4547-2018-phek-102a-12-6-2018.html (April 12, 2020)

Minoudis V. (2017). The educational Background of the Greek Elite Athletes / Three and their prospects for professional rehabilitation after the end of their athletic careers. Unpublished Master's Thesis at the University of Peloponnese, Sparta.

Rybaa, T. V. Ronkainenb, N. J., \& Selännec, H. (2015). Elite athletic career as a context for life design. Journal of Vocational Behavior, 88: 47-55. https://doi.org/10.1016/j.jvb.2015.02.002 
Stambulova, N., Ryba, T. V, \& Henriksen, K, (2020). Career development and transitions of athletes: the International Society of Sport Psychology Position Stand Revisited. International Journal of Sport and Exercise Psychology https://doi.org/10.1080/1612197X.2020.1737836

Stambulova, N., \& Wylleman, P. (2015). Dual career development and transitions. Psychology of sport and exercise, 21, 1-3. https://doi.org/10.1016/j.psychsport.2015.05.003

Wylleman P, Lavallee D (2004). A developmental perspective on transitions faced by athletes. In: M. R. Weiss (Ed.), Developmental sport and exercise psychology: A life span perspective. (pp. 503-523). Morgantown, Fitness Information Technologies.

Wylleman P, Reints A, De Knop P. (2013). A developmental and holistic perspective on athletic career development. In P. Sotiaradou, V. D. Bosscher. Managing high performance sport. (pp. 159-182). New York, Routledge.

\section{Copyright Disclaimer}

Copyright for this article is retained by the author(s), with first publication rights granted to the journal.

This is an open-access article distributed under the terms and conditions of the Creative Commons Attribution license (http://creativecommons.org/licenses/by/4.0/). 